\title{
Multiple Blood Meals as a Reproductive Strategy in Anopheles (Diptera: Culicidae)
}

\author{
HANS BRIEGEL AND EMANUEL HÖRLER
}

Institute of Zoology, University of Zürich, CH-8057 Zürich, Switzerland

\begin{abstract}
J. Med. Entomol. 30(6): 975-985 (1993)
ABSTRACT Multiple blood meals within one gonotrophic cycle were taken readily at 6-24-hr intervals by nulliparous female Anopheles albimanus Wiedemann. Up to five blood meals were ingested and with each blood meal, more primary follicles matured as well as some secondary ones. This produced an irregular oviposition pattern that questioned the concept of gonotrophic concordance. The first blood meal initiated limited vitellogenesis and the maturation of few follicles. Instead, protein was diverted to the synthesis of maternal, extraovarian lipid and protein deposits; fecundity increased with successive blood meals. This pattern of protein and energy utilization may be explained in terms of the low caloric lipid and protein content of nulliparous females before the first blood meal. In An. albimanus, a critical female body size, $\approx 0.25$ cal of lipid per female, was necessary for the initiation of oogenesis; below this threshold at least two blood meals were required for follicle maturation. Less than $10 \%$ of the caloric input from a blood meal was utilized in the synthesis of ovarian protein and lipids, whereas a similar percentage was transferred to maternal deposits of protein and lipid. In nonoogenic females, a replete blood meal increased total body protein and lipid by 17 and $113 \%$, respectively. Altogether, the efficiency of blood protein utilization was rather low, as indicated by losses of excretory nitrogen that regularly exceeded $75 \%$ of the input. Anopheles gambiae Giles and An. stephensi Liston also fed multiply, but fecundity was less affected. Instead, maternal deposits were synthesized from the blood meal in substantial amounts. In general, gonotrophic discordance also was found routinely in these anopheline species. The ratio of yolk protein to lipids varied inter- and intra-specifically, as well as among consecutive blood meals, indicating a considerable plasticity in the caloric distribution of these two yolk components.
\end{abstract}

KEY WORDS Anopheles spp., reproduction, multiple feeding

IN MOSQUITOES, reproduction is usually cyclic and initiated by a blood meal. Oviposition marks the end of this cycle, when the female is ready for another blood meal. For anopheline mosquitoes particularly, this cyclic mode of reproduction was called gonotrophic concordance by Swellengrebel (1929). Variations in this relationship were first observed by Swellengrebel (1929) in Anopheles labranchiae atroparvus Van Thiel, where females did not mature eggs after blood meals were ingested in the autumn, and, by de Buck \& Swellengrebel (1934) in Anopheles maculipennis messeae Falleroni, where females required more than one blood meal to complete a single gonotrophic cycle. The terms gonotrophic dissociation and gonotrophic discordance were coined by Swellengrebel (1929) for these situations, respectively. In the field, blood-fed mosquitoes have been collected attempting to feed on humans (e.g., Gillies \& De Meillon 1968, Magnarelli 1977). The frequency of multiple blood feeding in field-collected females has been found to vary from 5 to $50 \%$ in a number of Anopheles species (Senior White 1952, Davidson 1954, Smith \& Weitz 1959, Edman \& Downe
1964, Boreham \& Garrett-Jones 1973, Burkot et al. 1988). Reisen \& Aslamkhan (1976) presented evidence for three blood meals from eclosion to first oviposition in Anopheles culicifacies Giles. For Anopheles gambiae Giles and Anopheles funestus Giles, Hocking \& MacInnes (1948) suggested that at least two blood meals were necessary for each gonotrophic cycle. For these two species, Gillies $(1954,1955)$ reported gonotrophic discordance in $\approx 20 \%$ of the population. According to Gillies, the ovaries reached only the late resting stage with the first blood meal, and a second meal was required for complete maturation. A similar situation appears to occur in An. stephensi Liston and An. culicifacies (Reisen et al. 1986). Altogether, multiple blood meals appear to be a wide-spread requirement for completing the gonotrophic cycle of anophelines.

An earlier report (Briegel \& Rezzonico 1985) described an experiment with Anopheles albimanus Wiedemann, in which fecundity increased from 52 to 185 eggs per female when nullipars were fed three consecutive blood meals during a single oviposition cycle. This re- 
sult was indicative of gonotrophic discordance. Garrett-Jones (1970) clearly stated that bloodfeeding activity "may or may not correspond to the gonotrophic cycle" and "close correspondence is often assumed as the cycle itself in the absence of sufficient evidence."

Multiple blood meals also have been reported for culicine mosquitoes. In Culex tarsalis Coquillett, $43 \%$ of a population refed according to Bang \& Reeves (1942). Edman \& Downe (1964) found mixed blood meals in all of 14 species tested. More recently, in Aedes aegypti L., double blood meals were detected by Trpis \& Häusermann (1986) and multiple meals by Scott et al. (1993). Previously, gonotrophic discordance seemed to be associated primarily with hibernation (Roubaud 1929, Mitchell \& Briegel 1989), but the report by Scott et al. (1993) indicated frequent occurrence in tropical conditions and species more often than previously assumed. Multiple blood feedings might be the result of a first partial or interrupted blood meal. Indeed, Klowden \& Lea (1979b) demonstrated for Ae. aegypti that females could refeed within a limited time period after a small initial blood meal. Obviously, neural and humoral mechanisms have evolved, in most cases; preventing repeated blood meals within one gonotrophic cycle (Gwadz 1969; Klowden \& Lea 1979a, b). As a further safety mechanism against overloading, the oostatic hormone prevents additional oogenesis (Meola \& Lea 1972, Else \& Judson 1972).

The reports of reproductive aberrations in anophelines are descriptive in nature and gathered under field conditions in connection with malaria surveys or other epidemiological studies. Multiple meals have been attributed to interrupted feeding as a consequence of host defensive behavior. In the present report, we provide laboratory evidence that the nutritive state of anophelines rather than interrupted blood meals force repeated blood feeding. Low energy reserves at the time of eclosion (Briegel 1990b) form the metabolic basis for this multiple bloodmeal requirement. Female Anopheles appear to rely on a massive protein input from the blood meal for reproduction and for the acquisition of additional lipid and protein reserves.

\section{Materials and Methods}

The Anopheles used in this study were $A n$. (Nyssorhynchus) albimanus Wiedemann, strain "San Diego del Norte," An. (Cellia) stephensi Liston, strain of Indian origin (obtained from NIH), and An. (Cellia) gambiae Giles, strain 16c55. The taxonomic status of An. gambiae s. str. was confirmed by W. Maier (Bonn, Germany).

All larvae were reared at $27^{\circ} \mathrm{C}$ under $14: 10$ (L:D) h long-day conditions and were fed a highprotein diet comprising equal weights of lactalbumin, rat chow, and brewers yeast (Briegel 1990a, b). Imagoes were maintained in large cages ( 30 by 40 by $60 \mathrm{~cm}$ ) at $27^{\circ} \mathrm{C}$ and $85 \% \mathrm{RH}$ with access to sucrose ad lib under the same long-day conditions that included a 20 -min simulated sunrise and sunset. Stock colonies were fed weekly on 2 consecutive $\mathrm{d}$ for $20 \mathrm{~min}$ on a restrained guinea pig.

For experiments, mated females ( 1 or $2 \mathrm{~d}$ old) were fed on one of us (E. H.) who was not allergic to anopheline bites. Females were fed in groups of 20-30 until all stopped feeding as indicated by voluntary withdrawal of the proboscis. Subsequently, the females were checked individually for the presence of blood, then kept in beakers in groups of $20-30$. At a given interval, they were refed on the same subject for 10-20 min until all stopped feeding again. Each female then was inspected for the presence of fresh blood in the midgut by trans-illuminating her abdomen with a fiber optic halogen lamp. Even traces of fresh blood could be recognized around or above the dark bolus of the previous blood meal. The few females that did not refeed were kept as controls for single blood meals. All the females that refed were transferred individually to a reacting tube (14 by $100 \mathrm{~mm}$ ) to save their feces; a small cotton ball containing a drop of distilled water maintained humidity. After another $24 \mathrm{~h}$, the females were pooled in groups of 20 and were reexposed to the same host. Having fed to repletion, as judged again by withdrawal of the proboscis, they were examined a second time for the presence of fresh blood. The few that refused to feed were discarded. Fed females were transferred individually into new glass tubes to catch their feces during the next $24 \mathrm{~h}$. In some experiments, this procedure was repeated until five blood meals were taken. Females in these experiments were never offered sugar. After their last blood meals, females were kept individually in tubes for 48-60 h until defecation was complete and no black haematin remained in their midguts. Females then were anesthetized, their wing lengths measured as an estimate of body size (cubic value of wing length), the ovaries excised with fine needles, and the mature oocytes counted within a drop of $100 \%$ ethanol. Subsequently, these oocytes were collected with watchmaker's forceps and transferred to a test tube ( 10 by $70 \mathrm{~mm})$, fixed with ethanol at $90^{\circ} \mathrm{C}$ for $5 \mathrm{~min}$, then stored at room temperature until they were analyzed. Alternatively, females were allowed to oviposit overnight, the eggs were counted the next morning and fixed and analyzed in the same way. No differences in number or caloric content were detected between mature oocytes collected by ovarian dissection or oviposition. While dissecting the ovaries, the intestinal tract was routinely checked for traces of haematin; if present, the female was discarded because of incomplete or delayed defecation. Thus, the number of eggs 
matured, their total protein or lipid content, and the total excretory haematin value were determined for each female.

The biochemical analyses were performed as described previously (Briegel 1990a, b). Total proteins were estimated from total nitrogen through Kjeldahl digestion and subsequent Nesslerization (Minari \& Zilversmit 1963). Total lipids were determined according to the methods of Van Handel (1985b). Total carbohydrates of whole mosquitoes were measured with the hot anthrone reaction (Van Handel 1985a), which could not distinguish between glycogen and oligosaccharides. Carbohydrates never contributed more than a small percentage of the total caloric content; they were not given further consideration in this study.

Fecal material was eluted in $1 \%$ lithium carbonate to quantify haematin output (Briegel 1980). Based on the haematin readings per individual female, blood consumption could be determined retrospectively and the caloric input to the mosquito calculated (Briegel 1986). With this method, ingested protein (hemoglobin) actually digested and metabolized was measured; this eliminated hemoglobin losses as a result of bloodmeal concentration during feeding (Briegel \& Rezzonico 1985). The hemoglobin titer of the blood donor was monitored with Drabkin's solution (Briegel et al. 1979). His total blood protein was recorded simultaneously by the Kjeldahl procedure to convert the hemoglobin readings to total protein input for each blood meal.

In most cases, sufficient oocytes were present in single females for the analysis of the yolk protein or lipid. If $<30$ eggs were found, ovaries from two such females were pooled. Females were placed in small single cages $(20$ by $30 \mathrm{~mm}$ ) with a water-soaked pad of cellucotton for oviposition. These females subsequently were fixed with ethanol to analyze their protein or lipid reserves in comparison with their prereproductive conditions. Extraovarian nitrogen and lipid deposits were estimated either by subtracting ovarian values from the total female contents obtained shortly before oviposition, or by comparing caloric contents before blood feeding and shortly after oviposition. Analyses of carcasses would have falsified such determinations through leakage of haemolymph or inevitable losses of fat body tissue. All protein and lipid values were expressed in calories per female with 0.004 and $0.009 \mathrm{cal} / \mu \mathrm{g}$ as respective conversion factors. For single oocytes, the unit of millicalories $(1 \mathrm{mcal}=0.001 \mathrm{cal})$ was used. Means were compared by $t$ test statistics.

\section{Results}

Multiple blood meals in An. albimanus. When An. albimanus were fed to repletion on a human within 1-2 d of eclosion, they frequently refed

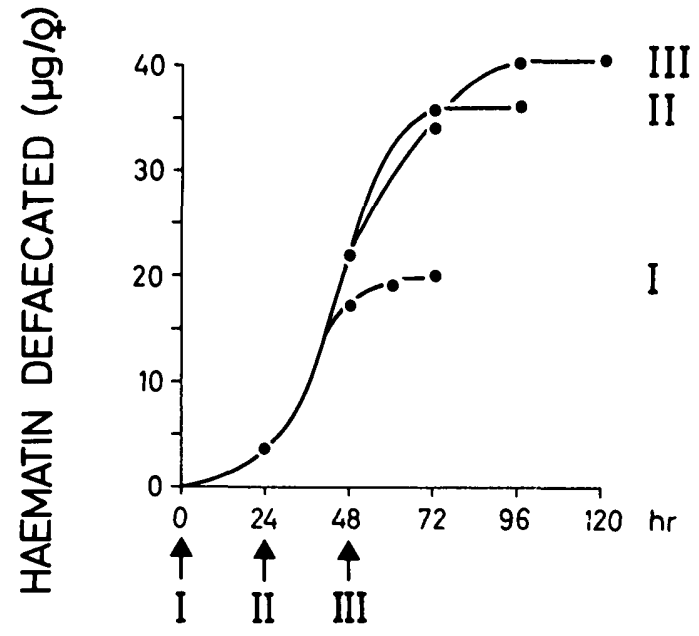

\section{TIME AFTER FIRST BLOOD MEAL}

Fig. 1. Haematin defecation by female An. albimanus fed three blood meals to repletion on a human host at daily intervals (arrows). Each point represents the measurement of one pool of excreta from 10-24 females.

three to five times. These females were inseminated and were not offered sugar during the experiment. To follow the digestion of repeated blood meals, haematin defecation was recorded during $120 \mathrm{~h}$ until oviposition had occurred (Fig. 1). The haematin readings could be assigned reliably to the actual number of blood meals given (I-III). The average volume of blood consumed by the females was estimated to be $3.3 \mu$ l for the first blood meal, $2.6 \mu$ l for the second meal, and $\approx 0.8 \mu \mathrm{l}$ for the third meal; total blood-meal volume was $6.7 \mu \mathrm{l}$ ( $5 \mathrm{cal}$ of blood protein).

To describe the effect of multiple feedings on oocyte maturation, some blood-fed females were dissected to measure the length of the yolk mass in the maturing follicles (and some were sacrificed for measuring midgut enzymes) (unpublished data). After the first blood meal $(n=306)$, the females were divided in two groups for recording oogenesis. In a group that imbibed only one blood meal $(n=108), 88$ females initiated oogenesis, and yolk was deposited into the follicles as shown in Fig. 2A. The maximal length of the yolk mass, $420 \mu \mathrm{m}(100 \%)$, was observed at $\approx 40 \mathrm{~h}$ in an average of 50 follicles per female. The remaining group of females received a second blood meal $(n=198)$. During the next 24 -h interval, 37 females were dissected, of which 23 continued to deposit yolk. The remaining $14 \mathrm{fe}-$ males started oogenesis after this second meal and followed the same biphasic line but with a considerably steeper slope that attained the final yolk length within $24 \mathrm{~h}$ (Fig. 2B). Thus, maturation was accelerated by a factor of 1.7 (24 versus $40 \mathrm{~h})$. 


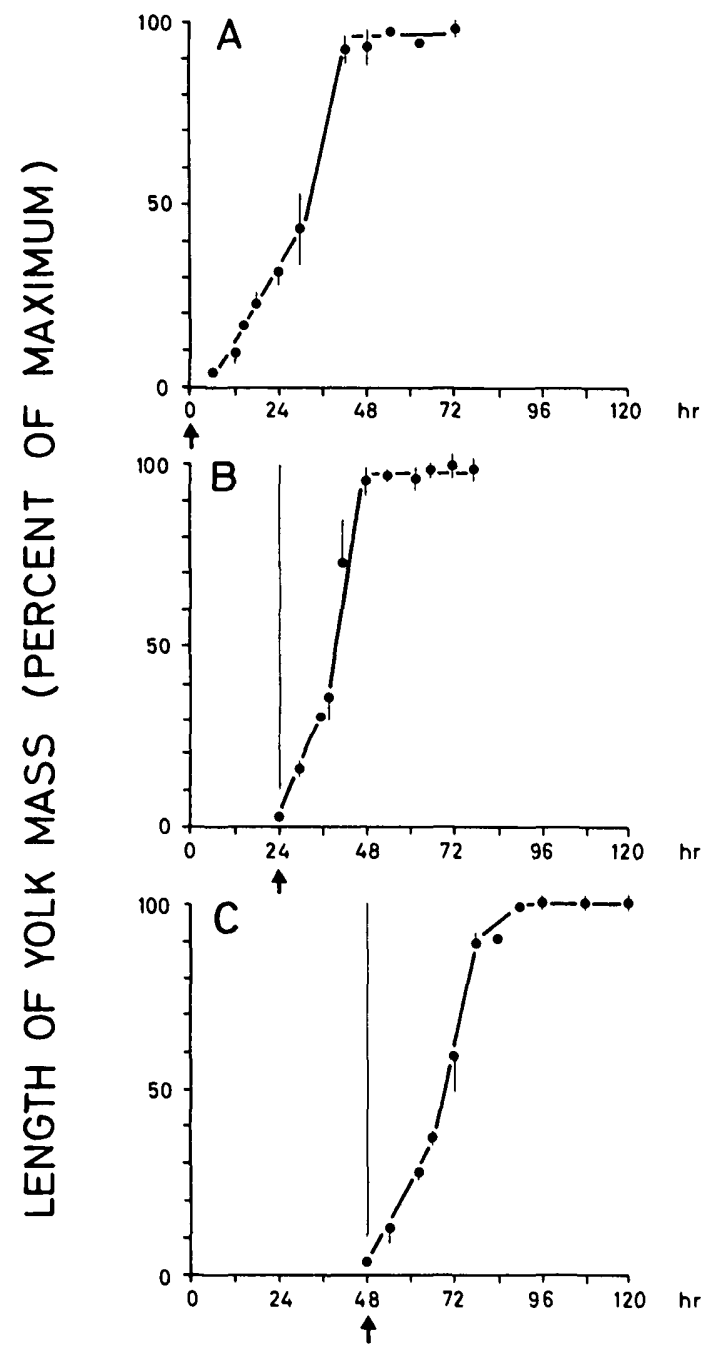

TIME AFTER FIRST BLOOD MEAL

Fig. 2. Oogenesis in An. albimanus traced by measuring the length of the yolk mass at various intervals after blood meals. Three blood meals were given at daily intervals to 1.5-d-old females from the same human host (arrows). Oocyte measurements for follicles stimulated by the first (A), the second (B), or the third (C) blood meals within the same cohort of females. Each point is the mean $( \pm S E)$ of two to seven follicles.

Of the group with three blood meals $(n=104)$, nearly half of the females $(n=48)$ started to deposit yolk into their penultimate follicles at the normal rate (Fig. 2C). Fig. 3 illustrates an ovary of a female $70-80 \mathrm{~h}$ after the first blood meal with a mature follicle, recognized by the chorionic features such as floats. Furthermore, this figure shows penultimate follicles in maturation with $325 \mu \mathrm{m}$ of yolk (77\% of the maximum). In the latter follicles, the chorionic structures were not yet differentiated because only 30-40 h had passed since their stimulation by the third blood meal. The number of mature

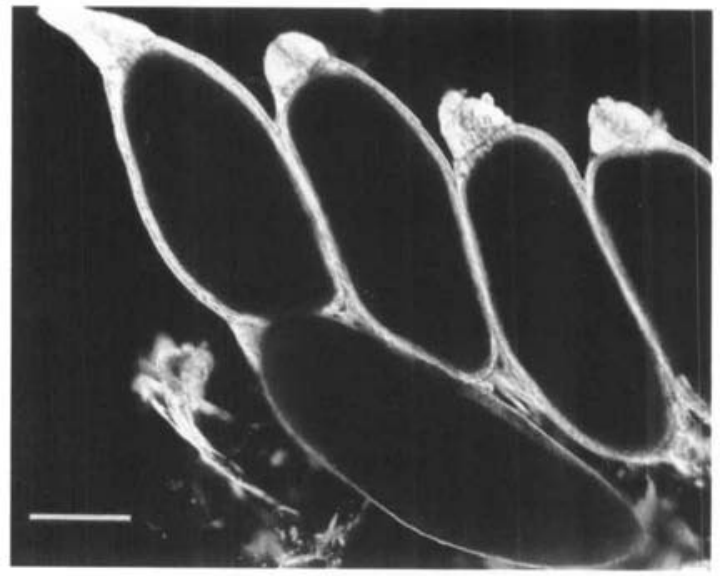

Fig. 3. Oogenesis in An. albimanus with three blood meals. Ovary dissected $72 \mathrm{~h}$ after the first blood meal (i.e., $48 \mathrm{~h}$ after the second and $24 \mathrm{~h}$ after the third). Ovariole at far left is still intact, showing a mature primary follicle (floats visible, $405 \mu \mathrm{m}$ of yolk length, $n=61$ ), and its secondary follicle in the process of maturation (311 $\mu \mathrm{m}$ of yolk length, $n=54)$. In the secondary follicles (three more are visible), the exochorionic structures have not yet differentiated. The germarium is recognized in all of them. The bar on the Nomarski-DIC photograph equals $100 \mu \mathrm{m}$.

oocytes per female was doubled from $76 \pm 20$ $(n=155)$ with two blood meals to $153 \pm 23(n=$ 41 ) with a third blood meal. The rate of yolk deposition always followed a biphasic pattern: a slower and a faster part with the transition period between yolk lengths of $130-170 \mu \mathrm{m}(30-40 \%$ of the maximum), irrespective of the feeding history.

To further investigate the frequency of multiple blood meals, female An. albimanus were exposed to the human host at shorter intervals. Even 6,8 , or $12 \mathrm{~h}$ after a replete blood meal, all females refed. Even with these shorter intervals, it was still possible to distinguish the most recent blood by transillumination. The bright red color of the recent meal was readily distinguished from the previous blood (characterized by a faint darkening of its color). This distinction was reliable only when screened within minutes after termination of feeding, because mixing of these blood meals started soon afterward because of an incomplete or weak peritrophic membrane formation at this time.

The metabolic fate of multiple blood meals was investigated by offering two blood meals within a 12-h interval. All females obtained the first blood meal at 24-26 h after eclosion and before they had access to either $10 \%$ sucrose or water. Afterward, they were kept with access to water for $2 \mathrm{~d}$ until the mature oocytes were counted and related to body size (Fig. 4). The control group was treated in the same way with only one blood meal. Even with sugar available, 

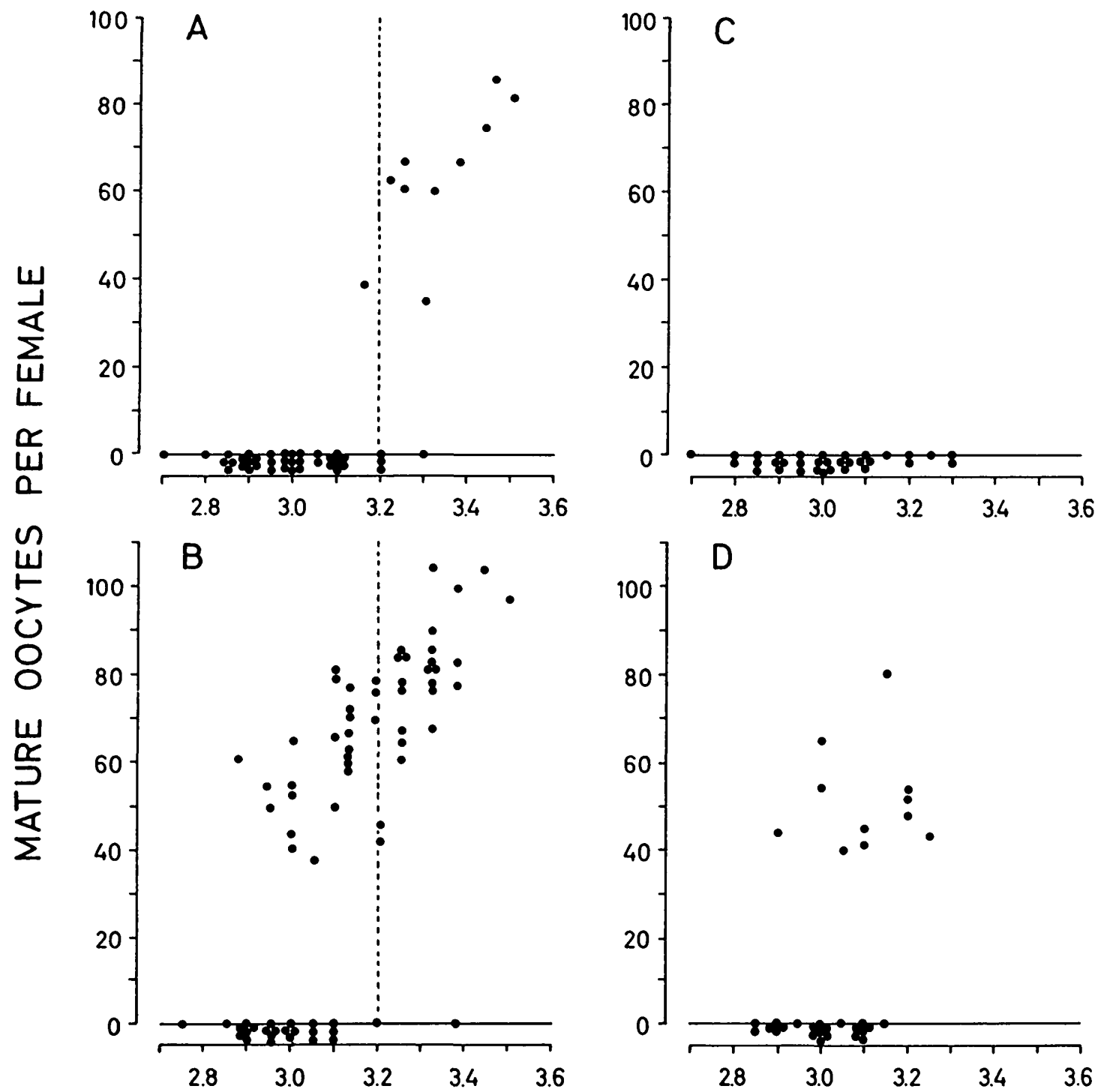

\section{WING LENGTH $(\mathrm{mm})$}

Fig. 4. Effect of body size (wing length) and prefeeding conditions on the fecundity of female An. albimanus after their first (A, C) or second (B, D) blood meal. Females were fed sucrose ad lib (A, B) or water (C, D) from eclosion until blood meal. The first blood meal was given $24-26 \mathrm{~h}$ after eclosion and the second $12 \mathrm{~h}$ later. Mature oocytes were counted by dissecting the ovaries $\approx 48 \mathrm{~h}$ after the blood meal. The dotted vertical lines indicate the threshold in body size required for oogenesis.

$81 \%$ of the females remained nonoogenic after their first blood meal; the remaining $19 \%$ produced $63 \pm 17$ eggs per female $(n=10)$ and had wing lengths $\geq 3.2 \mathrm{~mm}$ (Fig. $4 \mathrm{~A}$ ). With the second blood meal, fecundity did not increase significantly $(69 \pm 19$ eggs per female; $n=48 ; t=$ $0.987, \mathrm{df}=56, P>0.3)$, but $66 \%$ of these females initiated vitellogenesis, irrespective of their body size (Fig. 4B). In contrast, with prebloodmeal access only to water, none of the females entered oogenesis with one blood meal (Fig.
4C). With two blood meals, 33\% matured an average of $52 \pm 12$ eggs per female $(n=11$, Fig. 4D), irrespective of body size. When these females were analyzed for their prefeeding lipid reserves, females with access to only water had significantly fewer lipid reserves $(0.16 \pm 0.03 \mathrm{cal}$ per female; $n=50 ; t=7.993, \mathrm{df}=108, P<$ $0.001)$ than those with access to sugar $(0.23 \pm$ 0.06 cal per female, $n=60$ ).

When individual prefeeding lipid reserves were regressed on wing length (not shown), fe- 
Table 1. Caloric content of An. albimanus fed five consecutive blood meals at 24-h intervals on the same human host

\begin{tabular}{|c|c|c|c|c|c|c|c|c|c|}
\hline \multicolumn{3}{|c|}{ Blood meal $^{a}$} & \multicolumn{3}{|c|}{ Ovaries, cal } & \multicolumn{4}{|c|}{ Oocytes, mcal } \\
\hline Number & Volume, $\mu \mathrm{l}$ & Protein & $\begin{array}{l}\text { Protein } \\
(n)\end{array}$ & $\begin{array}{l}\text { Lipid } \\
(n)\end{array}$ & Ratio $\mathrm{P}: \mathrm{L}^{b}$ & No. per? & Protein & Lipid & Total \\
\hline $\begin{array}{l}1 \\
3 \\
5\end{array}$ & $\begin{array}{r}4.2 \\
8.5 \\
14.3\end{array}$ & $\begin{array}{r}3.15 \\
6.31 \\
10.63\end{array}$ & $\begin{array}{l}0.13(22) \\
0.48(38) \\
0.74(7)\end{array}$ & $\begin{array}{l}0.26(21) \\
0.33(37) \\
0.36(7)\end{array}$ & $\begin{array}{l}1: 2 \\
1: 0.7 \\
1: 0.5\end{array}$ & $\begin{array}{l}70(43) \\
168^{c} \\
260^{d}\end{array}$ & $\begin{array}{l}1.8 \\
3.7 \\
4.4\end{array}$ & $\begin{array}{l}3.6 \\
3.1 \\
2.6\end{array}$ & $\begin{array}{l}5.4 \\
6.8 \\
7.0\end{array}$ \\
\hline
\end{tabular}

a Bloodmeal data show protein values accumulated through blood meals 1 to 5 (cal per female).

${ }^{b} \mathrm{~L}$, lipid; $\mathrm{P}$, protein.

c Eight pools of 5-30 females each.

${ }^{d}$ Two pools of 6 and 34 females.

males with wings longer than $3.2 \mathrm{~mm}$ and access to sugar had lipid contents of $\geq 0.27$ cal. In contrast, the lipid content of females with access to water ranged from 0.11 to $0.25 \mathrm{cal}$. There appeared to be a threshold lipid level between 0.25 and $0.27 \mathrm{cal}$ per female, above which oogenesis was initiated with one blood meal. Below that level, however, an additional blood meal was required before oogenesis was started. With this supplementary blood meal, even the smallest females were able to initiate oogenesis (Fig. $4 \mathrm{~B}$ and $\mathrm{D})$ and in the larger females, fecundity rose to 100 eggs.

Caloric Allocation and Utilization of Bloodmeal Protein in Female An. albimanus. Because multiple blood meals improved fecundity and their effect appeared to depend on female lipid levels, we carried out a detailed quantitative analysis of the role of additional protein in yolk deposition and maternal metabolism. Over 300 females were fed five blood meals at 24 -h intervals. The total female protein and lipid was compared before the blood meal, before oviposition, and after oviposition. In addition, mature follicles were removed, counted, then analyzed for protein and lipids to estimate the caloric content of mature oocytes.

As shown in Table 1 , oogenic females produced $70 \pm 22$ eggs $(n=43)$ with one blood meal. In the mature ovaries, as well as in single oocytes, the caloric ratio of protein to lipid was 1:2. After three blood meals, fecundity increased to $168 \pm 22(n=8)$, and the caloric ratio of ovarian protein to lipid now was 1:0.7. Protein per oocyte doubled ( 3.7 mcal; $t=9.06, \mathrm{df}=63$, $P<0.001)$, whereas lipid per oocyte $(3.1 \mathrm{mcal})$ had decreased significantly when compared with oocytes matured with only one blood meal (3.6 mcal; $t=4.99, \mathrm{df}=62, P<0.001$ ).

Data in Table 1 also indicated that fecundity increased with five blood meals, attaining an average of 260 eggs per female. The caloric proportion of total yolk protein to lipid was 1:0.5. This shift was caused by a nearly 6-fold increase in yolk protein plus a 1.5-fold increase in yolk lipid in mature ovaries compared with one blood meal. However, protein per single oocyte more than doubled (from 1.8 to $4.4 \mathrm{mcal}$ ), whereas the lipid per oocyte was reduced by roughly one- quarter (from 3.6 to 2.6 mcal; $t=5.10, \mathrm{df}=26$, $P<0.001$ ) (Table 1). Thus, with subsequent blood meals, the total caloric content of mature oocytes (protein plus lipid) increased from 5.4 (first blood meal) to 6.8 (third), and finally to 7.0 mcal per oocyte (fifth). Thus, total yolk per oocyte was enhanced with each additional blood meal because of considerable flexibility in the ratios of protein and lipids within the maturing oocytes. However, the total yolk mass synthesized per female never exceeded $10-13 \%$ of the caloric blood protein input, indicating that there were limitations in the efficiency of utilizing the blood meal for vitellogenesis.

To test for alternative metabolic routes in the utilization of host blood protein, we compared female protein and lipid before the blood meal and after oviposition with one and three blood meals (Table 2). After the first blood meal, half of the females matured an average of $46 \pm 12(n=$ 20 ) eggs, utilizing $9.7 \%$ of bloodmeal protein for the synthesis of yolk protein plus lipid. Oogenesis was not detected in the remaining females $(n=23)$. Instead, they showed a net gain of 0.10 cal of protein and 0.41 cal of lipid, comprising $15.9 \%$ of the caloric value of the blood meal. With three blood meals, the females matured an average of $78 \pm 21(n=40)$ eggs, utilizing 0.45 cal for the synthesis of yolk protein plus lipid (6.8\% of the caloric protein input). In addition, they synthesized $0.16 \mathrm{cal}$ of extraovarian protein and $0.29 \mathrm{cal}$ of extraovarian lipid deposits, representing a net gain of $6.7 \%$ in maternal deposits.

To demonstrate the priority in synthesis of maternal deposits, sugar-fed female An. albimanus were given enemas that contained protein insufficient for oogenesis, because by this route the mechanism of protein concentration was abolished (Briegel \& Rezzonico 1985). With $1 \mu$ l of human blood ( 0.91 cal protein), none of the females initiated oogenesis but within $48 \mathrm{~h}$, their total body protein had increased significantly $(t=3.643, \mathrm{df}=34, P<0.001)$ from 0.54 to 0.67 cal per female (Table 3 ), utilizing $14 \%$ of the protein input. Total lipid insignificantly increased from 0.79 to $0.87 \mathrm{cal}$ per female $(t=$ 0.985 , df $=33, P>0.3$ ), representing $9 \%$ of the bloodmeal input. Therefore, a total of $23 \%$ of the bloodmeal protein was retained by nonoogenic 
Table 2. Gain of protein and lipid reserves in female $A$ n. albimanus fed one to three blood meals at 24-h intervals on the same human host

\begin{tabular}{|c|c|c|c|c|}
\hline Parameter & Protein $(n)$ & Lipid (n) & Total & $\begin{array}{c}\text { \% Caloric bloodmeal } \\
\text { input }\end{array}$ \\
\hline Preblood meal & $0.55 \pm 0.08(37)$ & $0.09(38)$ & 0.92 & - \\
\hline One blood meal & 3.20 & 一 & - & 100 \\
\hline Ovaries ( $46 \pm 12$ eggs) & $0.12 \pm 0.05(10)$ & $0.07(10)$ & 0.31 & 9.7 \\
\hline Nonoogenic 9 & $0.65 \pm 0.06(12)$ & $0.23(11)$ & 1.43 & - \\
\hline$\%$ Gain per nonoogenic ${ }^{a}$ & $0.10 \approx 17 \%$ & $0.41 \approx 113 \%$ & 0.51 & 15.9 \\
\hline Three blood meals & 6.58 & - & 一 & 100 \\
\hline Ovaries ( $78 \pm 21$ eggs) & $0.18 \pm 0.13(20)$ & $0.08(20)$ & 0.45 & 6.8 \\
\hline Postoviposition $?$ & $0.71 \pm 0.09(24)$ & $0.18(32)$ & 1.36 & - \\
\hline$\%$ Gain per ${ }^{a}$ & $0.16 \approx 28 \%$ & $0.28 \approx 78 \%$ & 0.44 & 6.7 \\
\hline
\end{tabular}

Values are mean calories per female $\pm \mathrm{SE}$.

${ }^{a}$ Percentage of prebloodmeal values.

females and was used to augment maternal protein and lipid.

With $2-\mu$ l enemas (1.83 cal protein), a third of the females $(n=5)$ showed limited oogenesis. The remaining two-thirds $(n=11)$ now had a total body protein content of $0.84 \mathrm{cal}$ per female ( $16 \%$ of the blood meal input; $t=10.207, \mathrm{df}=39$, $P<0.001$ ) and of $1.25 \mathrm{cal}$ per female of lipid (25\% of the blood meal input; $t=4.658, \mathrm{df}=28$, $P<0.001)$. Therefore, a total of $41 \%$ of the bloodmeal protein was retained by the nonoogenic females, improving their content of protein and lipids by 55 and $58 \%$, respectively. Consequently, bloodmeal protein was utilized predominantly for the synthesis of maternal deposits, and the improvement of fecundity was postponed.

To resolve the metabolic fate of sequential blood meals, five blood meals were given to females at 24-h intervals and oviposition was recorded in 12-h intervals during $144 \mathrm{~h}$. Feeding success was consistently $>90 \%$. Immediately after the third blood meal, $65 \%$ of the individually blood-fed females oviposited $61 \pm 13$ eggs $(n=$ 97). After blood meal 4, an average of $55 \pm 19$ eggs $(n=56)$ was deposited by $67 \%$ of the surviving females during the next day. After blood meal 5 , another $69 \pm 34$ eggs $(n=23)$ were laid by $32 \%$ of the fed females within $24 \mathrm{~h}$, and during the last collecting interval, $90 \pm 27$ eggs $(n=$ 48) were laid by $68 \%$ of the females. Total fecundity amounted to an average of 275 eggs per female (range, 107-480 eggs). Finally, $168 \mathrm{~h}$ after the first blood meal, these females had empty ovaries, and the female protein and lipids were $0.81 \pm 0.10 \mathrm{cal}(n=35)$ and $0.82 \pm 0.18 \mathrm{cal}(n=$ 33 , respectively. The corresponding values for teneral females of the same body size was 0.80 cal of protein and $0.22 \mathrm{cal}$ of lipid. Despite the processing of five blood meals and production of several hundred eggs per female, total lipids had more than tripled (from 0.22 to $0.82 \mathrm{cal}$ ).

In conclusion, this experiment indicated that oviposition regularly took place within 48-60 h of a blood meal, each of which appeared to initiate maturation of a new set of follicles. Each "wave" of oviposition comprised between 50 and 100 eggs per female. Consequently, batches of $>150$ eggs, as observed above and reported earlier (Briegel \& Rezzonico 1985), appeared to be an artifact because of oviposition deprivation. Therefore, the double follicles shown in Fig. 3 might be the consequence of the lack of oviposition sites or oviposition stimuli. Furthermore,

Table 3. Gain of protein and lipid reserves in female An. albimanus with blood meals given by enema

\begin{tabular}{|c|c|c|c|}
\hline Parameter & Protein $(n)$ & Lipid $(n)$ & Total \\
\hline $\begin{array}{l}\text { Preblood meal } \\
\text { Human blood, } 1 \mu \mathrm{l}\end{array}$ & $\begin{array}{l}0.54 \pm 0.09(25) \\
0.91 \pm 0.11(5)\end{array}$ & $0.79 \pm 0.2^{a}(25)$ & 1.33 \\
\hline Nonoogenic ${ }^{\mu}$ & $0.67 \pm 0.11(11)$ & $0.87 \pm 0.23(10)$ & 1.54 \\
\hline $\begin{array}{l}\% \text { Gain per } \% \\
2 \mu l\end{array}$ & $\begin{array}{l}0.13=24 \%^{b}(=14 \%)^{c} \\
1.83\end{array}$ & $0.08=10 \%^{b}(=9 \%)^{c}$ & 0.21 \\
\hline $\begin{array}{l}\text { Nonoogenic } ? \\
\% \text { Gain per } \%\end{array}$ & $\begin{array}{l}0.84 \pm 0.08(16) \\
0.30=55 \%^{b}(=16 \%)^{c}\end{array}$ & $\begin{array}{l}1.25 \pm 0.15 \quad(5) \\
0.46=58 \%^{b}\left(=25 \%^{c}\right)\end{array}$ & $\begin{array}{l}2.09 \\
0.76\end{array}$ \\
\hline $\begin{array}{l}\text { Preblood meal } \\
\text { Rodent blood, } 1 \mu l\end{array}$ & $\begin{array}{l}0.53 \pm 0.08(11) \\
0.79 \pm 0.01(7)\end{array}$ & $0.51 \pm 0.09(10)^{c}$ & 1.04 \\
\hline $\begin{array}{l}\text { Nonoogenic } ? \\
\text { \% Gain per } ?\end{array}$ & $\begin{array}{l}0.81 \pm 0.13(4) \\
0.27=51 \%^{b}(=34 \%)^{c}\end{array}$ & $\begin{array}{ll}0.66 \pm 0.19 & (4) \\
0.15=30 \%^{b} & (1)(=19 \%)^{c}\end{array}$ & $\begin{array}{l}1.46 \\
0.43\end{array}$ \\
\hline
\end{tabular}

Values are mean calories per female $\pm \mathrm{SE}$. Volume and source of blood was varied.

${ }^{a}$ Gain in percentage of preblood meal female content ().

${ }^{b}$ Gain in percentage of blood meal content.

c The preblood meal lipid content of 0.79 cal was higher than in Table 2 because the females had access to sugar in this experiment. 
Table 4. Caloric content of An. stephensi and An. gambiae fed three consecutive blood meals at 24-h intervals on the same human host

\begin{tabular}{|c|c|c|c|c|c|c|c|c|c|c|}
\hline \multirow{2}{*}{ Species } & \multicolumn{3}{|c|}{ Blood meal $^{a}$} & \multicolumn{3}{|c|}{ Ovaries, cal } & \multicolumn{4}{|c|}{ Oocytes, mcal } \\
\hline & Number & Volume & Protein & Protein & Lipid & Ratio $\mathrm{P}: \mathrm{L}^{b}$ & Number & Protein & Lipid & Total \\
\hline \multirow[t]{2}{*}{ An. stephensi } & 1 & 4.63 & 3.44 & 0.15 & 0.31 & $1: 2.0$ & 70 & 1.9 & 4.3 & 6.2 \\
\hline & 3 & 7.28 & 5.41 & 0.31 & 0.33 & $1: 1.1$ & 80 & 3.7 & 4.4 & 8.1 \\
\hline \multirow[t]{2}{*}{ An. gambiae } & 1 & 2.85 & 2.12 & 0.03 & 0.22 & $1: 8.8$ & 50 & 0.6 & 3.8 & 4.0 \\
\hline & 3 & 5.01 & 3.72 & 0.13 & 0.29 & $1: 2.2$ & 76 & 1.6 & 3.7 & 5.3 \\
\hline
\end{tabular}

Values are mean calories or millicalories per female $\pm \mathrm{SE}$.

${ }^{a}$ Bloodmeal data show protein values accumulated through blood meals 1 to 3 (calories per female).

${ }^{b} \mathrm{~L}$, lipid; P, protein.

protein reserves are acquired with the first few blood meals (Tables 2 and 3 ) and lipid reserves are conserved at a fairly high level.

Multiple Blood Meals in An. stephensi. To test whether observations on An. albimanus could be generalized to other anophelines, An. stephensi was offered three consecutive blood meals at 24-h intervals. The females refed at these intervals, and blood feeding easily could have been continued at this pace. With their first blood meal, $70 \pm 16(n=44)$ eggs matured. Before the blood meal, the females were equicaloric in protein $(0.64 \pm 0.11 \mathrm{cal}$ per female, $n=38)$ and lipid $(0.64 \pm 0.13 \mathrm{cal}$ per female, $n=39)$. After depositing the first batch of eggs, their protein remained the same $(0.68 \pm 0.08 \mathrm{cal}$ per female, $n=$ 7 ), but their lipid content was reduced by $40 \%$ to $0.38 \pm 0.11 \mathrm{cal}$ per female $(n=8 ; t=5.355, \mathrm{df}=$ $45, P<0.001)$. Surprisingly, after three blood meals, fecundity rose to only $80 \pm 13(n=50)$ eggs per female, a small but significant increase $(t=3.342, \mathrm{df}=92, P<0.01)$. In these females, the total ovarian lipid was nearly the same as in females fed only once $(0.31$ versus $0.33 \mathrm{cal}$; Table 4), but the ovarian protein had doubled $(0.15$ versus $0.31 \mathrm{cal}$; Table 4$)$. These changes also became evident when comparing the protein and lipid per oocyte. The oocyte lipid was the same whether females were fed one or three blood meals, but oocyte protein had doubled (Table 4). Although multiple blood meals were evident in this species, hardly any new oocytes were stimulated to undergo oogenesis. Subsequent blood meals were used to supplement the protein content of oocytes already in maturation. In addition, females with three blood meals showed an increase of their total nonovarian protein content from 0.64 to $0.84 \mathrm{cal}$ per female, representing an increase of $31 \%$ compared with prefeeding conditions $(t=7.025, \mathrm{df}=63, P<0.001)$.

Protein acquisition from the blood meals was accompanied by a significant lipid reduction of $33 \%$ from 0.64 to 0.43 cal per female $(t=6.366$, $\mathrm{df}=63, P<0.001)$. Taken together, the total caloric content (protein plus lipid) of each female after metabolizing three blood meals was the same after oviposition as it was before feeding: 1.27 and 1.28 cal, respectively. This might imply some sort of reallocation of reserve components; i.e., the inevitable loss of $33 \%$ of lipids through oogeneses and oviposition was compensated by a net gain of $31 \%$ of protein compared with prebloodmeal conditions. Therefore, in $A n$. stephensi, multiple blood meals appear to improve the yolk and maternal protein from the first blood meal as a possible compensation for the concomitant loss of lipids.

Multiple Blood Meals in An. gambiae. Females were kept on sucrose ad lib from eclosion for $\approx 12 \mathrm{~h}$, after which they were fed on a human host. These females $(n=28)$ digested and excreted their blood meal but did not mature any eggs. A similar result was observed when they fed $24 \mathrm{~h}$ after eclosion. At the age of $48 \mathrm{~h}, 40 \%$ of the females matured $46 \pm 19$ eggs $(n=7)$ and at $72 \mathrm{~h}$, this percentage rose to $73 \%$ with $47 \pm 15$ eggs $(n=13)$ per female. Females that had fed but failed to initiate oogenesis had synthesized maternal, extraovarian deposits of protein and lipid to the extent of 7 and $13-17 \%$ of the caloric bloodmeal input, respectively. In this way the prefeeding protein content was markedly improved. Structural changes in preresting stage oocytes were not followed. Although biting, feeding, and digestion were possible at $12 \mathrm{~h}$, female metabolism was not competent yet to allow oogenesis. Synthesis of yolk components developed only after $24 \mathrm{~h}$ of imaginal life, indicating once more the priority of reserve acquisition over vitellogenesis in teneral females.

All female An. gambiae avidly refed when offered the same host within 12 or $24 \mathrm{~h}$. At $6 \mathrm{~h}$ after a blood meal, the females were reluctant to refeed, and of the $10 \%$ that did, the second blood meal could not be recognized reliably by our transillumination test because the first blood meal was still bright red in color. With three blood meals, fecundity rose to $76 \pm 21$ eggs per female $(n=75, t=6.588, \mathrm{df}=115, P<0.001)$, which is $50 \%$ more than with the first blood meal (50 \pm 17 eggs, $n=42$ ). The dominance of lipid over protein in the yolk resulting from one blood meal was reduced with three blood meals (Table 4). This change occurred exclusively on the level of yolk protein, because yolk lipid remained constant at 3.7-3.8 mcal per oocyte. With three blood meals, female metabolism had increased extraovarian protein values by $25 \%$. Concomitantly, 
however, lipids were reduced by $24 \%$, indicating a redistribution of maternal reserves when enhancing fecundity through repetitive blood meals, similar to An. stephensi.

\section{Discussion}

Three Anopheles vectors of malaria took multiple blood meals on a human host, irrespective of their nutritional or gonotrophic status. In our experiments, where host-seeking may have been bypassed by close contact with the host, three to five blood meals were taken readily at intervals of 6,12 , or $24 \mathrm{~h}$. This result might indicate the absence of neural as well as hormonal biting inhibitions at least from $6 \mathrm{~h}$ onward, contrary to sugar-fed Ae. aegypti (Klowden \& Lea 1979b). Rapid refeeding led us to postulate a strategy of blood meal acquisition and utilization in anophelines different from that known for the culicines, which are characterized by the evolution of clear-cut gonotrophic cycles. In general, the neuro-endocrine system (Clements 1963; Meola \& Lea 1972; Lea 1975; Klowden \& Lea $1979 a, b)$ enforces gonotrophic concordance. In contrast, anophelines having fed "to repletion" avidly refeed when exposed to the same host at almost any intervals. Recently, the validity of gonotrophic concordance was questioned by Edman et al. (1992), even in Ae. aegypti in view of their blood-feeding pattern. In Anopheles, multiple feeding is facilitated by an efficient mechanism of blood protein concentration during feeding (Briegel \& Rezzonico 1985) which is followed later by diuresis. The first blood meal was used primarily for the synthesis of maternal reserves, whereas sequential blood meals were utilized for improving fecundity by synthesizing additional yolk protein and yolk lipid. Thus, full fecundity in An. albimanus and An. gambiae was reached only through continued yolk production by repeated blood feeding.

Initiation of yolk synthesis after the first blood meal depended on female body size. Teneral anophelines were characterized by limited reserves per unit body size (Briegel 1990a, b). In An. albimanus, females with wing lengths of $<3.2 \mathrm{~mm}$ did not start oogenesis with one blood meal but required additional protein input. Teneral An. albimanus females with wing lengths of $3.2 \mathrm{~mm}$ contained $0.25 \mathrm{cal}$ of lipids. (Briegel $1990 \mathrm{~b})$. All the smaller females with $<0.25 \mathrm{cal}$ of lipids required a second blood meal for the stimulation of oogenesis. This critical level is crucial for the initiation of oogenesis following a blood meal, confirming the threshold size described previously (Briegel 1990b).

Hocking \& MacInnes (1948), working on An. gambiae and An. funestus, reported that "females ... sometimes feed daily"; this was related to frequent flights of females of various gonoactive status in and out of huts to rest in- doors during daytime (Gillies \& De Meillon 1968). Gillies (1955) already found the "pregravid phase of ovarian development" in An. funestus to require multiple feedings in the field. All these behavioral adaptations of anophelines appear to compensate the low lipid contents per female. In the case of sufficient lipid reserves through carbohydrate feeding and a large enough blood meal ( $>0.5$ cal of protein), vitellogenesis is possible for a batch of 40-50 eggs. But with an opportunity to feed on a host, additional blood meals readily are ingested to improve both reserves and fecundity. Therefore, the complex and refined endocrine regulations of gonotrophic concordance would be a hindrance. In Ae. aegypti, there also was a minimal energetic status required for oogenesis (Briegel 1985). Unless a minimal energy requirement of $1 \mathrm{cal}$ per female was attained by preblood meal caloric content plus caloric protein input from blood feeding, oogenesis was not initiated (H. B., unpublished data).

In recent field studies, Edman et al. (1992) and Scott et al. (1993) reported that multiple blood meals occurred regularly in Ae. aegypti under natural conditions in preference to sugar meals. Based on earlier results (Briegel 1990a), and not having access to thorough investigations on the various physiological parameters, we believe that this multiple blood feeding represents another mechanism contrasting with that described herein for the anophelines. In Ae. aegypti, the subsequent meals appear to improve (in a nutritive sense) a gonotrophic cycle already underway along the line reported by Lea et al. (1978), rather than to stimulate additional follicles for maturation, as in Anopheles. The less efficient lipogenic potential of Anopheles indeed sharply contrasts with Aedes or Culex (Van Handel 1965, 1984; Mitchell \& Briegel 1989; Briegel 1990a).

In Ae. aegypti, all reproductive processes typically ensue on a higher level in absolute caloric terms, which in turn may require strict regulation to prevent females from temporarily overloading while feeding on protein from a host. In contrast to the energetic dumping characterizing culicine reproduction, anophelines appear to operate permanently at their energetic minimum, which leads to behavioral and nutritional constraints for the acquisition of additional protein as provided by multiple blood meals.

In spite of all these adaptations, the comparatively low efficiency of the utilization of these blood meals remains an enigma. Even after consecutive blood meals with a 3 -fold increase in fecundity, there was always an excretory nitrogen loss of up to $75 \%$ of the input. Further experiments are required to relate the oogenic efficiencies to the enormous protein catabolism.

The dynamics of yolk deposition was interesting to follow for two reasons. First, it was biphasic under all circumstances. There was a slower 
rate of yolk deposition until $30-40 \%$ of the maximal yolk length was reached, followed by a clearly steeper and rapid segment. Rates increased by $\approx 50 \%$, and durations were about half the first segment. Similar biphasic yolk curves have been observed for various species (H. B., unpublished data). More interesting, however, was the absolute time requirement for the maturation of the oocytes. In An. albimanus after the first blood meal, maximal yolk length was reached within $40 \mathrm{~h}$. With a second blood meal, additional follicles started to deposit yolk, but these reached maturity within half the time. With a third blood meal, still another set of oocytes entered vitellogenesis, again requiring $\approx 40 \mathrm{~h}$ to reach maximal yolk length. Consequently, when proper ovipositional stimuli were provided, almost continuous oviposition was observed.

Depending on their dietary history, a high flexibility in the yolk composition of Anopheles eggs was observed. In An. albimanus given one, three, or five blood meals, yolk protein increased by a factor of nearly $2.5(1.8,3.9,4.4 \mathrm{mcal}$, respectively), whereas yolk lipids decreased by one-third (3.6, 3.1, 2.6 mcal, respectively). In $A n$. gambiae and An. stephensi, oocyte values were similar. With three blood meals, their protein per oocyte increased $\approx 2.5$ times, whereas the lipid per oocyte of these species was not affected by the additional protein input. As far as yolk lipids are concerned, An. gambiae and An. stephensi were different from An. albimanus. This also was true for the number of maturing oocytes, because in the former two species this figure remained almost constant despite additional blood meals, but in An. albimanus it clearly had an enhancing effect. Under such complex metabolic conditions, recording the frequencies of blood meals and counting eggs may be misleading for recognizing gonotrophic cycles. It appears that gonotrophic cycles are doubtful, for certain Anopheles at least, as clearly stated by GarrettJones (1970). Accordingly, we are left with the impression that gonotrophic discordance prevails in many anopheline species. Thus in Anopheles, mixed meals do not necessarily represent interrupted feedings. Instead, they may reflect a well-adapted strategy, primarily to ameliorate female reserves and improve the fecundity from subsequent blood meals. In contrast, in the culicines, mixed blood meals are thought to indicate interrupted feedings, because hostseeking behavior was found clearly to operate under narrowly defined conditions (Klowden 1990). In this context, the infrequent double feedings reported for culicines are exceptional, whereas multiple feedings appear to be adaptive for anophelines. Although gathered under controlled or manipulated (or both) laboratory conditions, our results demonstrate the physiological and metabolic potential of the species investigated and they may elucidate the concept of gonotrophic cycles in anopheline vector species.

\section{Note Added in Proof}

To refute the argument of multiple blood meals as an artifact of forced-feeding under laboratory conditions we have carried out the following experiment. An. albimanus $(n=197)$ were bloodfed and exposed $12 \mathrm{~h}$ later to one of us at night while sleeping under a bednet of $\approx 2 \mathrm{~m}^{3}$ volume. After a 2 -h exposure the females were collected and analyzed in comparison to controls $(n=71)$ having had only one blood meal: $81 \%$ of the females refed a second time and significant increases $(P<0.001)$ were observed for mean hematin excretion $(+44 \%)$ and fecundity $(+32 \%)$.

\section{Acknowledgments}

We thank S. Zaba and I. Flückiger for dependable rearing of the mosquito colonies, and R. Haigis for excellent technical assistance. We appreciate the critical reading of the manuscript and the help given by $R$. Graf (all from the University of Zürich). Substantial improvements suggested by referees and the editor are kindly acknowledged. Financial support was received from the Swiss National Science Foundation.

\section{References Cited}

Bang, F. B. \& W. C. Reeves. 1942. Mosquitoes and encephalitis in the Yakima Valley, Washington. III. Feeding habits of Culex tarsalis Coq., a mosquito host of the viruses of Western equine and St. Louis encephalitis. J. Infect. Dis. 70: 273-274.

Boreham, P.F.L. \& C. Garrett-Jones. 1973. Prevalence of mixed blood meals and double feeding in a malaria vector (Anopheles sacharovi Favre). Bull. W.H.O. 48: 605-614.

Briegel, H. 1980. Determination of uric acid and hematin in a single sample of excreta from blood-fed insects. Experientia 36: 1428.

1985. Mosquito reproduction: incomplete utilization of the blood meal protein for oogenesis. J. Insect Physiol. 31: 15-21.

1986. Protein catabolism and nitrogen partitioning during oogenesis in the mosquito Aedes aegypti. J. Insect Physiol. 32: 455-462.

1990a. Metabolic relationship between female body size, reserves, and fecundity of Aedes aegypti. J. Insect Physiol. 36: 165-172.

1990b. Fecundity, metabolism, and body size in Anopheles (Diptera: Culicidae), vectors of malaria. J. Med. Entomol. 27: 839-850.

Briegel, H. \& L. Rezzonico. 1985. Concentration of host blood protein during feeding by anopheline mosquitoes (Diptera: Culicidae). J. Med. Entomol. 22: 612-618.

Briegel, H., A. O. Lea \& M. J. Klowden. 1979 . Hemoglobinometry as a method for measuring blood meal sizes in mosquitoes. J. Med. Entomol. 15: 235-239. 
Burkot, T. R., P. M. Graves, R. Paru \& M. Lagog. 1988. Mixed blood feeding by the malaria vectors in the Anopheles punctulatus complex (Diptera: Culicidae). J. Med. Entomol. 25: 205-213.

Clements, A. N. 1963. The physiology of mosquitoes. Pergamon, London.

Davidson, G. 1954. Estimation of the survival-rate of anopheline mosquitoes in nature. Nature 174: 792-793.

De Buck, A. \& N. H. Swellengrebel. 1934. Behaviour of Dutch Anopheles atroparvus and messeae in winter under artificial conditions. Riv. Malariol. 13: 404-416 (in Clements 1963).

Edman, J. D. \& A.E.R. Downe. 1964. Host-blood sources and multiple-feeding habits of mosquitoes in Kansas. Mosq. News 24: 154-160.

Edman, J. D., D. Strickman, P. Kittayapong \& T. W. Scott. 1992. Female Aedes aegypti (Diptera: Culicidae) in Thailand rarely feed on sugar. J. Med. Entomol. 29: 1035-1038.

Else, J. G. \& C. L. Judson. 1972. Enforced eggretention and its effects on vitellogenesis in the mosquito Aedes aegypti. J. Med. Entomol. 9: 527530.

Garrett-Jones, C. 1970. Problems of epidemiological entomology as applied to malariology, pp. 168180. In Miscellaneous Publications 7, Entomological Society of America, College Park, MD.

Gillies, M. T. 1954. The recognition of age-groups within populations of Anopheles gambiae by the pre-gravid rate and the sporozoite rate. Ann. Trop. Med. Parasitol. 48: 58-74.

1955. The pre-gravid phase of ovarian development in Anopheles funestus. Ann. Trop. Med. Parasitol. 49: $320-325$.

Gillies, M. T. \& B. De Meillon. 1968. The Anophelinae of Africa South of the Sahara (Ethiopian zoogeographical region). Publ. South African Inst. Med. Res. 54, 343 pp. Johannesburg.

Gwadz, R. W. 1969. Regulation of blood meal size in the mosquito. J. Insect Physiol. 15: 2039-2044.

Hocking, K. S. \& D. G. MacInnes. 1948. Notes on the bionomics of Anopheles gambiae and A. funestus in East Africa. Bull. Entomol. Res. 39: 453-465.

Klowden, M. J. 1990. The endogenous regulation of mosquito reproductive behavior. Experientia 46: 660-670.

Klowden, M. J. \& A. O. Lea. 1979a. Humoral inhibition of host-seeking in Aedes aegypti during oocyte maturation. J. Insect Physiol. 25: 231-235.

1979b. Abdominal distention terminates subsequent host-seeking behaviour of Aedes aegypti following a blood meal. J. Insect Physiol. 25: 583-585.

Lea, A. O. 1975. The control of reproduction by a blood meal: the mosquito as model for vector endocrinology. Acta Trop. 32: 112-115.

Lea, A. O., H. Briegel \& H. M. Lea. 1978. Arrest, resorption, or maturation of oocytes in Aedes aegypti: dependence on the quantity of blood and the interval between blood meals. Physiol. Entomol. 3: $309-316$.

Magnarelli, L. A. 1977. Physiological age of mosquitoes (Diptera: Culicidae) and observations on partial blood-feeding. J. Med. Entomol. 13: 445450.

Meola, R. \& A. O. Lea. 1972. Humoral inhibition of egg development in mosquitoes. J. Med. Entomol. 9: 99-103.

Minari, O. \& D. B. Zilversmit. 1963. Use of KCN for stabilization of color in direct Nesslerization of Kjeldahl digests. Anal. Biochem. 6: 320-327.

Mitchell, C. J. \& H. Briegel. 1989 . Inability of diapausing Culex pipiens (Diptera: Culicidae) to use blood for producing lipid reserves for overwinter survival. J. Med. Entomol. 26: 318-326.

Reisen, W. K. \& M. Aslamkhan. 1976. Observations on the swarming and mating behaviour of Anopheles culicifacies Giles in nature. Bull. W.H.O. 54: 155-158.

Reisen, W. K., F. Mahmood, S. Niaz, K. Azra, T. Parveen, R. Mukhtar, Y. Aslam \& T. F. Siddiqui. 1986. Population dynamics of some Pakistan mosquitoes: temporal changes in reproductive status, age structure and survivorship of Anopheles culicifacies, An. stephensi and Culex taeniorhynchus. Ann. Trop. Med. Parasitol. 80: 77-95.

Roubaud, E. 1929. Cycle autogène d'attente et generations hivernales suractives inapparentes chez le moustique commun, Culex pipiens. C. R. Acad. Sci. (Paris) 188: 735-738.

Scott, T. W., G. G. Clark, L. H. Lorenz, P. H. Amerasinghe, P. Reiter \& J. D. Edman. 1993. Detection of multiple blood feeding in Aedes aegypti (Diptera: Culicidae) during a single gonotrophic cy. cle using a histologic technique. J. Med. Entomol. 30: 94-99.

Senior White, R. A. 1952. Studies on the bionomics of Anopheles aquasalis Curry 1932. Ind. J. Malariol. 6: 29-72.

Smith, A. \& B. Weitz. 1959. The feeding habits of Anopheles gambiae, with particular reference to subsidiary hosts. Ann. Trop. Med. Parasitol. 53: 414-415.

Swellengrebel, N. H. 1929. La dissociation des fonctions sexuelles et nutritives (dissociation gonotrophique) d'Anopheles maculipennis comme cause du paludisme dans les pays-bas et ses rapports avec "l'infection domicilaire". Ann. Inst. Past. (Paris). 43: 1370-1389 (in Clements 1963).

Trpis, M. \& W. Häusermann. 1986. Dispersal and other population parameters of Aedes aegypti in an African village and their possible significance in epidemiology of vector-borne diseases. Am. J. Trop. Med. Hyg. 35: 1263-1279.

Van Handel, E. 1965. The obese mosquito. J. Physiol. 181: 478-486.

1984. Metabolism of nutrients in the adult mosquito. Mosq. News 44: 573-579.

1985a. Rapid determination of glycogen and sugars in mosquitoes. J. Am. Mosq. Control Assoc. 1: 299301.

1985b. Rapid determination of total lipids in mosquitoes. J. Am. Mosq. Control Assoc. 1: 302-304.

Received for publication 11 November 1992; accepted 10 May 1993. 